\title{
Communication Skills in the Age of COVID-19
}

\author{
Anthony Back, MD; James A. Tulsky, MD; and Robert M. Arnold, MD
}

$I^{n}$ n a new, cruel way, the coronavirus 2019 (COVID-19) pandemic has revealed limitations in medical capacity that amplify the challenges that clinicians already face in communicating with patients about serious illness. The most recent estimates of the effects of the pandemic describe a scenario that none of us have ever seen: Demand for hospital beds in the United States will exceed capacity by 64175 acute care beds and 17309 intensive care beds; over the next 4 months, clinicians are projected to witness 81114 deaths (1). These statistics, though, are merely a 30000 -foot view of the territory that clinicians are seeing now, as they grapple with patients and families on the ground about how to prepare, what is happening, and what to expect.

For clinicians who have received training in evidencebased methods to communicate with patients with serious illness, many of these conversations will feel familiar. Delivering serious news and discussing goals of care still work as heuristics for COVID-19-related illness (2), although clinicians will face an extra measure of COVID-19related apprehension, uncertainty, and fear. But clinicians are also being confronted with new communication tasks that none of us have faced before, including proactive COVID-19 planning for patients who are already frail with other serious illnesses, facilitating virtual goodbyes between family members and dying patients with restricted access, and explaining decisions on why a particular patient will not receive a scarce resource.

For clinicians who have not had such training, the COVID-19 pandemic is likely to be a demoralizing experience. The shortfall in system capacity will guarantee that they will run out of time repeatedly, and the usual phrases will be out of place in new situations. For clinicians equipped with a deep understanding of communication principles and a flexible repertoire, however, their expertise is already enabling them to innovate and adapt.

It is not too late for clinicians to learn these skills. We have used 5 years of experience with scaling up serious illness communication skills training-our nonprofit startup VitalTalk (www.vitaltalk.org) has reached at least 30000 clinicians-to create a series of just-intime tips, talking maps, and video demonstrations we have made freely available (3). Our approach, which has shown positive outcomes in clinician behavior (4), patient quality of life (5), and patient trust (6), is based on 3 core principles. First, dealing with emotion is more important than giving lots of information. Unless we acknowledge the fear, sadness, and anxiety that patients and families experience, they will not absorb the information they need. Second, information is best delivered in small packets that start with a headline. When we embed bad news in a long, technical medical narrative, our patients lose the thread and miss the news.
The third principle states that patient values should be at the heart of medical treatment plans. When we elicit values from patients, they feel heard and understood even when the care plans bend toward what is medically possible.

The caveat introduced by COVID-19 is that our third principle yields to crisis standards of care. Under crisis standards, the ethical foundation shifts from individual values to population-based resource allocation that maximizes the most good for the largest number of people (7). Clinicians should become familiar with their state standards, which differ somewhat across the United States. When systems and clinicians are operating under crisis standards, patients will not have some choices. Triage committees will make decisions for patients that may hasten death. In these circumstances, clinicians will need to shift away from the third principle. Instead of eliciting values that drive care, clinicians will need to explain the care that is possible, refrain from offering treatments or interventions that aren't available for that patient, and instead share what crisis standards mean for them (Figure). This does not require that clinicians stop listening, stop talking about what's important, or stop empathizing-those skills will be more important than ever. But in a crisis, the third principle must yield.

For clinicians, we expect that the experience of working under crisis standards will be far-reaching, with repercussions that persist for a long time (8). For us, the COVID-19 pandemic has evoked feelings that we haven't visited since the first phase of AIDS: huge uncertainty, deep vulnerability, and gruesome anecdotes. Yet back then, we were also humbled and inspired by clinicians who stepped up heroically to care for those first HIV-positive patients (9), and that personal experience shaped much of the work in communication we do now. Our hope is that the attention we bring to the communication that lies at the heart of clinical care could enable us and our colleagues to emerge from this pandemic with more wisdom and kindness. For patients and families, we hope that care from a clinician who communicates their caring could mitigate a measure of the suspicion and mistrust that seems likely to be another legacy of COVID-19.

We are not suggesting that communication skills alone are going to be a silver bullet for clinician moral distress, exhaustion, and grief in the face of COVID-19. Communication is only one part-albeit an essential part- of what clinicians will need to survive well. What our experience in training thousands of clinicians to communicate better has shown us is that it is possible to get better at facing inequality, suffering, and dying, regardless of the circumstances. It takes a sense of purpose, systems that commit resources, and high-quality

This article was published at Annals.org on 2 April 2020. 
Figure. Talking maps for communication during the COVID-19 pandemic.

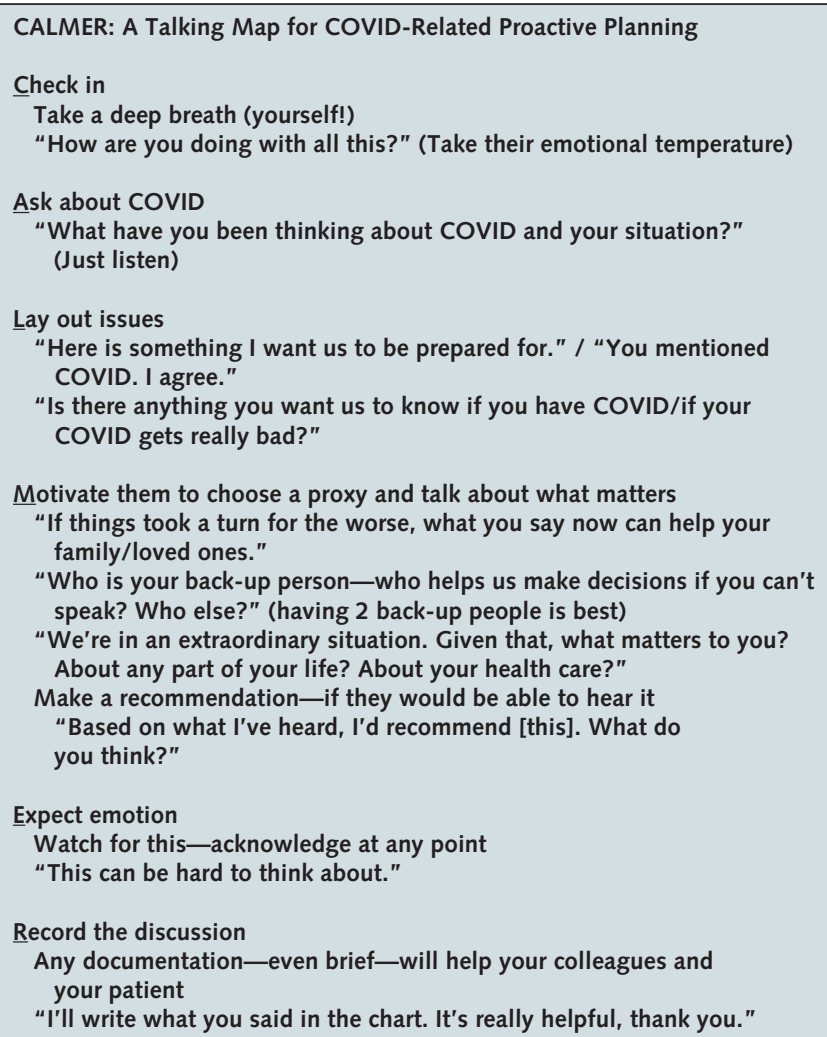

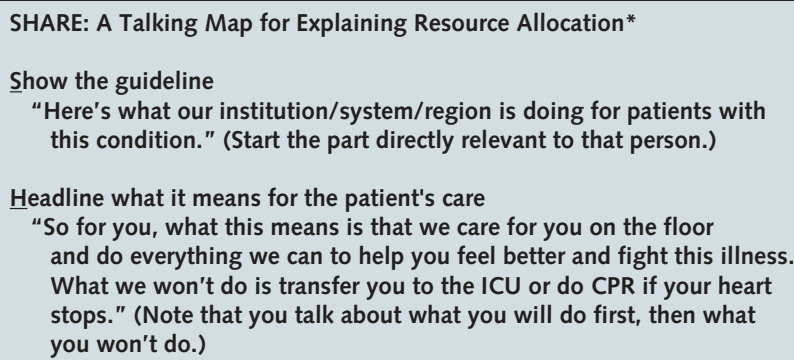

*This talking map is used only when an institution has declared use of crisis standards of care, or a surge state. When the crisis standards or surge are discontinued, this map should no longer be used.

COVID = coronavirus disease $; C P R=$ cardiopulmonary resuscitation; $I C U=$ intensive care unit.

communication skills. We can rise to this challenge. Each of us who cares about communication can reach out to our colleagues to encourage, mentor, coach, and support each other; advocate within our systems; and keep ourselves healthy, while we do the work of our calling: communication, compassion, and healing.

From University of Washington and VitalTalk, Seattle, Washington (A.B.); Dana-Farber Cancer Institute, Boston, Massachusetts, and VitalTalk, Seattle, Washington (J.A.T.); and University of Pittsburgh, Pittsburgh, Pennsylvania, and VitalTalk, Seattle, Washington (R.M.A.).

Disclosures: Dr. Arnold reports personal fees from VitalTalk and UpToDate outside the submitted work. Authors not named here have disclosed no conflicts of interest. Disclosures can also be viewed at www.acponline.org/authors/icmje /ConflictOfInterestForms.do?msNum=M20-1376.

Corresponding Author: Anthony L. Back, MD, University of Washington, Harborview Medical Center, 325 9th Avenue, Seattle,WA 98104; e-mail, tonyback@uw.edu.

Current author addresses and author contributions are available at Annals.org.

\section{References}

1. Murray C. Forecasting COVID-19 impact on hospital bed-days, ICU-days, ventilator days and deaths by US state in the next 4 months. Seattle: Institute of Health Metrics and Evaluation, Univ of Washington; 2020. Accessed at www.healthdata.org/sites/default /files/files/research_articles/2020/covid_paper_MEDRXIV-2020 -043752v1-Murray.pdf on 1 April 2020.

2. Back AL, Arnold RM, Tulsky JA. Mastering Communication with Seriously III Patients: Balancing Honesty with Empathy and Hope. New York: Cambridge Univ Pr; 2009.

3. Back AL. COVID-Ready Communication Skills: A Playbook of VitalTalk Tips. Seattle: VitalTalk; 2020.

4. Back AL, Arnold RM, Baile WF, et al. Efficacy of communication skills training for giving bad news and discussing transitions to palliative care. Arch Intern Med. 2007;167:453-60. [PMID: 17353492] 5. Rogers JG, Patel CB, Mentz RJ, et al. Palliative care in heart failure: the PAL-HF randomized, controlled clinical trial. J Am Coll Cardiol. 2017;70:331-341. [PMID: 28705314] doi:10.1016/j.jacc.2017.05.030 6. Tulsky JA, Arnold RM, Alexander SC, et al. Enhancing communication between oncologists and patients with a computer-based training program: a randomized trial. Ann Intern Med. 2011;155:593-601. [PMID: 22041948] doi:10.7326/0003-4819-155-9-201111010-00007

7. Committee on Guidance for Establishing Standards of Care for Use in Disaster Situations. Crisis Standards of Care: A Systems Framework for Catastrophic Disaster Response. Washington D.C.: National Academies of Sciences, Engineering, and Medicine; 2012. 8. Benedek DM, Fullerton C, Ursano RJ. First responders: mental health consequences of natural and human-made disasters for public health and public safety workers. Annu Rev Public Health. 2007; 28:55-68. [PMID: 17367284]

9. Oppenheimer GM, Bayer R. AIDS Doctors: Voices From the Epidemic. New York: Oxford Univ Pr; 2002. 
Current Author Addresses: Dr. Back: University of Washington, Harborview Medical Center, 325 9th Avenue, Seattle, WA 98104.

Dr. Arnold: University of Pittsburgh, 3459 5th Avenue, \# MUH 9, Pittsburgh, PA 15213.

Dr. Tulsky: Dana-Farber Cancer Institute, 450 Brookline Avenue, Boston, MA 02215.
Author Contributions: Conception and design: A.L. Back, J.A. Tulsky

Analysis and interpretation of the data: R.M. Arnold, A.L. Back Drafting of the article: A.L. Back, J.A. Tulsky

Critical revision for important intellectual content: R.M. Arnold, A.L. Back, J.A. Tulsky

Final approval of the article: R.M. Arnold, A.L. Back, J.A. Tulsky Administrative, technical, or logistic support: A.L. Back

Collection and assembly of data: A.L. Back 